\title{
ESTUDO DA ABSORÇÃO DE ÓLEO EM REVESTIMENTOS DE PRODUTOS EMPANADOS
}

\author{
R. F. ALMEIDA ${ }^{1}$, J. HILLESHEIN JR ${ }^{1}$, A. C. SILVA ${ }^{1}$, P. P. SILVA ${ }^{1}$ \\ ${ }^{1}$ Universidade Federal do Triângulo Mineiro, Departamento de Engenharia Química \\ E-mail para contato: priscila.silva@uftm.edu.br
}

\begin{abstract}
RESUMO - Em busca de praticidade e economia de tempo, os consumidores estão optando por produtos semi-prontos e benéficos à saúde. A principal obtenção desses produtos é através do processo de fritura, que confere sabor, textura e aparência muito apreciados. Neste trabalho desenvolveu-se uma cobertura de revestimento para alimentos empanados com adição de solução de amido de milho com concentração $30 \%$, com o intuito de diminuir a absorção de óleo durante o processo de fritura. Foram selecionados o óleo de soja, que é o mais utilizado no mercado nacional e a farinha de rosca para realização desse estudo. Essa solução de amido foi pré-gelatinizada e adicionada às amostras de farinha de rosca em quantidades diferentes $(0,3,5,7$ e 10g). As amostras de farinha de rosca padrão e tratadas com a solução de amido de milho foram submetidas ao processo de secagem e posterior fritura em condições similares ao processo industrial. O teor de lipídeos foi quantificado através do extrator do tipo Soxhlet, com o éter de petróleo como solvente extrator, exprimindo que a menor condição de absorção de óleo entre as amostras de farinha de rosca foi a tratada com $10 \mathrm{~g}$ da solução de amido, garantindo que o amido reduz a absorção de óleo durante o processo de fritura. Além disso, os teores de ácidos graxos livres e o índice de peróxidos das amostras de óleo foram investigados a fim de averiguar que o nível de degradação do óleo de fritura estava abaixo dos limites aceitáveis ANVISA.
\end{abstract}

\section{INTRODUÇÃO}

Devido ao estilo de vida bastante agitado, o consumidor vem buscando alternativas para otimizar o tempo de preparo das refeições no dia a dia, optando por produtos de fácil e rápido preparo. Com isso, a produção de produtos empanados vem conquistando seu espaço no mercado, pois, além de sua conveniência, possuem odor, sabor e aparência muito apreciados (Dill et al., 2009). Um dos produtos mais consumidos são os chamados Nuggets ou Steaks, que são produtos cárneos revestidos de cobertura apropriada. A farinha de cobertura, além de proporcionar aparência e textura ao produto, serve também para impedir a perda de água durante o processo de fritura. Pensando no público que não tem muito tempo para preparar as suas refeições, busca-se incrementar esses alimentos semi-prontos, modificando a sua composição nutricional através da adição de amido na etapa de cobertura (Flores, 2012).

A adição de amido na farinha de cobertura é responsável pela aderência desse revestimento ao produto, além de diminuir a absorção de óleo durante o processo de fritura. $\mathrm{O}$ amido possui baixo custo e age diretamente nas propriedades físico-químicas, alterando e 
controlando características como textura, aparência, umidade, consistência e estabilidade no armazenamento do produto. Ao escolher o tipo de farinha de cobertura, deve-se atentar a sua granulometria, pois, grãos mais finos são mais utilizados no processamento de empanados influenciando diretamente no sabor e no aspecto do produto final após a fritura. Os óleos e gorduras comumente comercializados são: óleo de soja, canola, girassol, milho, de palma, entre outros, os quais são constituídos principalmente por triglicerídeos. Porém, o mais utilizado é o óleo de soja, devido a sua grande produção mundial e por apresentar odor e sabor suave característico (Dill et al., 2010).

Todavia, a ingestão em excesso de óleos e gorduras torna-se prejudicial à saúde, podendo ocasionar vários tipos de doenças crônicas como diabetes e obesidade. É necessário atentar-se com a utilização de frituras de forma excessiva e também com a quantidade de repetições que o óleo ou a gordura foi usado. Essas repetições podem comprometer a qualidade do óleo devido à troca de umidade do alimento com o meio de fritura e a alta temperatura, aumentando assim o índice de acidez e peróxidos (Batista et al., 2010). Assim, este trabalho teve como objetivo estudar a influência da adição de uma solução de amido prégelatinizada à farinha de rosca, utilizada como revestimento externo em produtos empanados, visando à redução da absorção de gordura na etapa de pré-fritura. Foram quantificados também os ácidos graxos livres (AGL), e os índices de peróxidos (IP) existentes no óleo antes e após o processo de fritura a fim de aferir a sua qualidade final.

\section{MATERIAIS E MÉTODOS}

\subsection{Classificação granulométrica da farinha de rosca}

Para a determinação da faixa granulométrica da farinha de rosca comercial foram selecionadas uma série de peneiras: 20, 30, 40, 50, 60, 70, 80 e 100 mesh. Pesou-se uma amostra de $100 \pm 0,27 \mathrm{~g}$ que foi direcionada ao peneiramento. Foram pesadas cada peneira antes e após o peneiramento contendo o material retido. Este procedimento foi realizado em duplicata e o software STATISTICA ${ }^{\circledR}$ foi utilizado para a avaliação dos modelos.

\subsection{Análise de umidade da farinha de rosca}

A técnica foi realizada no Analisador de Umidade por infravermelho da marca GEHAKA, modelo IV2500. As análises foram realizadas à $105^{\circ} \mathrm{C}$ durante $30 \mathrm{~min}$. Para todos os testes foram utilizadas $5 \mathrm{~g}$ de amostra .

\subsection{Caracterização do óleo de soja}

\subsection{1. Índice de acidez}

Para a determinação do índice de acidez utilizou-se a metodologia proposta pelo Instituto Adolfo Lutz (2008).

\subsection{2. Índice de peróxidos}

Para a determinação do índice de peróxidos utilizou-se o método Cd3d-63 da American Oil Chemists' Society (AOCS, 2009).

\subsection{Solução de amido gelatinizado}


Mediu-se $100 \mathrm{ml}$ de água destilada em um béquer, o qual foi colocado em uma manta aquecedora para ser aquecido à uma temperatura de $65^{\circ} \mathrm{C}$. Posteriormente adicionou-se $30 \mathrm{~g}$ de amido de milho misturando-se continuamente até que a solução ficasse homogênea e com uma viscosidade na qual fosse possível pulverizar.

\subsection{Pré tratamento da farinha de rosca}

O pré tratamento da farinha de rosca consistiu em pulverizar quantidades diferentes da solução de amido gelatinizado sobre a farinha. Este processo foi realizado através de um recipiente com bico pulverizador contendo a solução de amido gelatinizado. Em seguida, foram pesados $10 \mathrm{~g}$ de farinha de rosca na balança semi-analítica, onde a amostra recebeu diferentes quantidades $(0,3,5,7$ e $10 \mathrm{~g})$ da solução de amido gelatinizado (30\% em massa).

\subsection{Processo de fritura}

A unidade experimental de fritura era composta por um fogão, uma panela com revestimento de teflon contendo 1 litro de óleo de soja, uma peneira cônica de aço inox, um termômetro e um cronômetro. Para evitar variações todos os experimentos foram feitos com a mesma quantidade de óleo, onde o cone foi imerso até atingir o fundo da panela a fim de atingir uma altura ideal para encobrir a amostra. Em seguida a amostra foi imersa no óleo $\left(\mathrm{T}=194^{\circ} \mathrm{C}\right.$ ) durante $28 \mathrm{~s}$. Essas condições de temperatura e tempo foram selecionadas com o objetivo de reproduzir as condições operacionais das indústrias de fabricação de produtos empanados (LUCAS, 2010). Após a fritura, a amostra permaneceu durante $30 \mathrm{~min}$ à temperatura ambiente para resfriamento em um papel toalha para retirar o excesso de óleo.

\subsection{Teor de lipídios}

As amostras previamente resfriadas foram pesadas, envoltas em um papel filtro e submetidas ao equipamento extrator do tipo Soxhlet da marca MARCONI, modelo MA 49, para extração lipídica com o éter de petróleo como solvente extrator. O processo de extração permaneceu durante $4 \mathrm{~h}$ e, após esse tempo os reboilers foram levados à estufa na temperatura de $105^{\circ} \mathrm{C}$ por cerca de $1 \mathrm{~h}$ a fim de garantir que todo o éter fosse retirado da amostra. Este procedimento foi feito para cada concentração de farinha de rosca frita, em triplicata. Vale ressaltar que se colocou um branco para comparação dos resultados.

\section{RESULTADOS E DISCUSSÕES}

\subsection{Granulometria}

A partir dos resultados de distribuição granulométrica da farinha de rosca foi possível concluir que a farinha de rosca comercial é composta por partículas muito finas com diâmetro médio de partículas igual a $0,4547 \mathrm{~mm}$. Analisando o modelo de distribuição que melhor se ajusta aos dados experimentais, três modelos de distribuição, Gates-Gaudin e Schumann (GGS), Rosin-Rammler e Bennet (RRB) e Sigmóide foram ajustados à análise granulométrica. Na Tabela 1, têm-se expressos os parâmetros obtidos para os modelos em estudo. 
Tabela 1 - Parâmetros e correlação dos modelos

\begin{tabular}{|c|c|c|c|c|c|c|c|}
\hline Modelos & $\mathrm{m}$ & $\mathrm{k}$ & $\mathrm{D}$ & $\mathrm{n}$ & $\mathrm{D}_{50}$ & $\mathrm{p}$ & $\mathrm{R}^{2}$ \\
\hline GGS & 1,6543 & 0,8283 & & & & & 0,9475 \\
\hline RRB & & & 0,5425 & 3,1321 & & & 0,9937 \\
\hline Sigmóide & & & & & 0,4400 & 1,0000 & 0,5073 \\
\hline
\end{tabular}

O modelo de melhor ajuste aos dados experimentais foi o RRB, visto que este apresenta o maior valor de $\mathrm{R}^{2}$ e uma análise de resíduos versus preditos sem linhas de tendência.

\subsection{Umidade}

Através da regressão polinomial utilizando o software Excel foi possível a obtenção da equação de umidade que representa o melhor ajuste da curva e das correlações quadráticas das diferentes condições em que a farinha de rosca foi submetida. O teor de umidade para a farinha de rosca padrão foi igual a $11,74 \%$ e o período de secagem foi de 54 min, conforme Tabela 2. $\mathrm{O}$ aumento da adição da solução do amido à farinha de rosca gerou um aumento no teor de umidade e consequentemente maior tempo de secagem. Avaliou-se também a umidade do óleo de soja antes e após do processo de fritura que resultou em torno de $0,4 \%$ de umidade e não houve variação.

Tabela 2- Valores de umidade da farinha de rosca

\begin{tabular}{|c|c|c|c|c|c|c|c|c|c|c|}
\hline \multicolumn{2}{|c|}{ Umidade em função do tempo para a adição de diferentes massas de solução de amido na farinha de rosca } \\
\hline \hline Tratamento & $\begin{array}{c}\text { Solução } \\
\text { de } \\
\text { amido }\end{array}$ & A1 & A2 & A3 & A4 & A5 & A6 & R2 & $\begin{array}{c}\% \text { de } \\
\text { umidade }\end{array}$ & $\begin{array}{c}\text { Tempo } \\
\text { de } \\
\text { secagem }\end{array}$ \\
\hline 1 & $0 \mathrm{~g}$ & $-2 \mathrm{E}-07$ & $1 \mathrm{E}-05$ & $-0,0003$ & 0,0008 & 0,0123 & 11,703 & 0,9955 & 11,740 & 54 \\
\hline 2 & $3 \mathrm{~g}$ & & $-7 \mathrm{E}-06$ & 0,0008 & $-0,0287$ & 0,3485 & 26,958 & 0,9956 & 27,845 & 77 \\
\hline 3 & $5 \mathrm{~g}$ & & $-9 \mathrm{E}-06$ & 0,0008 & 0,0223 & 0,2068 & 35,068 & 0,9962 & 35,450 & 79 \\
\hline 4 & $7 \mathrm{~g}$ & & $-7 \mathrm{E}-06$ & 0,0007 & $-0,0232$ & 0,2589 & 40,009 & 0,9971 & 40,595 & 80 \\
\hline 5 & $10 \mathrm{~g}$ & & $-2 \mathrm{E}-06$ & 0,0001 & 0,0005 & $-0,088$ & 46,979 & 0,9958 & 46,480 & 91 \\
\hline
\end{tabular}

\section{2. Índice de acidez e Índice de peróxido}

A Tabela 3 apresenta os resultados de índices de acidez e índice de peróxidos obtidos neste trabalho para todas as amostras. A quantidade de ácidos graxos livres e o índice de peróxidos obtidos para todas as amostras está muito abaixo do limite estabelecido pela ANVISA (IA:0,9\% e IP:10). Assim, pode-se afirmar que os óleos não sofreram forte degradação e que podem ser utilizados novamente para outros procedimentos de fritura. 
Tabela 3: Resultados de ácidos graxos livres e índice de peróxido

\begin{tabular}{|c|c|c|}
\hline $\begin{array}{c}\text { Amostra de } \\
\text { óleo de soja }\end{array}$ & $\begin{array}{c}\text { Ácidos graxos } \\
\text { livres (\%) }\end{array}$ & $\begin{array}{c}\text { Índice de peróxidos } \\
\text { (meq/kg de amostra) }\end{array}$ \\
\hline \hline Óleo virgem & $0,05 \%$ & $0,08 \pm 0,0002$ \\
\hline $0 \mathrm{~g}$ de amido & $0,06 \%$ & $0,26 \pm 0,02$ \\
\hline $3 \mathrm{~g}$ de amido & $0,04 \%$ & $0,38 \pm 0,02$ \\
\hline $5 \mathrm{~g}$ de amido & $0,03 \%$ & $0,58 \pm 0,0004$ \\
\hline $7 \mathrm{~g}$ de amido & $0,03 \%$ & $0,58 \pm 0,1$ \\
\hline $10 \mathrm{~g}$ de amido & $0,08 \%$ & $0,28 \pm 0,02$ \\
\hline
\end{tabular}

\subsection{Teor de lipídios}

A Tabela 4 apresenta a média da quantidade de óleo extraída de cada amostra de farinha de rosca tratada com a solução de diferentes concentrações de amido gelatinizado, além da porcentagem de óleo correspondente a essa extração. Em todas as análises, houve a utilização de uma amostra padrão (amostra das farinhas de rosca não submetida ao processo de fritura) referente a cada amostra para comparação do teor de absorção lipídico.

Tabela 4: Porcentagem de óleo absorvido

\begin{tabular}{|c|c|c|}
\hline \multicolumn{3}{|c|}{ Processo de extração de óleo } \\
\hline \hline Amostra & Óleo extraído & $\%$ de óleo \\
\hline Branco $0 \mathrm{~g}$ & 0,0315 & 0,61 \\
\hline $0 \mathrm{~g}$ & 0,2856 & 18,18 \\
\hline Branco $3 \mathrm{~g}$ & 0,2261 & 4,64 \\
\hline $3 \mathrm{~g}$ & 1,1597 & 26,18 \\
\hline Branco 5g & 0,0391 & 0,77 \\
\hline $5 \mathrm{~g}$ & 1,0029 & 18,65 \\
\hline Branco 7g & 0,0235 & 0,45 \\
\hline $7 \mathrm{~g}$ & 0,9935 & 16,67 \\
\hline Branco $10 \mathrm{~g}$ & 0,0139 & 0,27 \\
\hline $10 \mathrm{~g}$ & 0,7738 & 13,93 \\
\hline
\end{tabular}

As amostras em branco apresentam baixo índice de extração e consequentemente menor teor lipídico, isto se dá, pois, as amostras não tiveram contato com o óleo. Assim, esta porcentagem de gordura é referente apenas ao teor lipídico presente na composição da farinha. O maior teor de absorção de óleo obtido é o da farinha de rosca tratada com $3 \mathrm{~g}$ de amido gelatinizado que corresponde a $26,18 \%$ enquanto que o menor teor de absorção é o da farinha de rosca tratada com $10 \mathrm{~g}$ de amido gelatinizado, cujo valor é de $13,93 \%$. Isto implica que a adição de amido foi satisfatória e acarretou em uma diminuição na absorção de óleo durante a fritura. A adição de amido gelatinizado à farinha de rosca cria um filme que atua como barreira à perda de umidade e a absorção de óleo. Porém, vale ressaltar que a adição de $10 \mathrm{~g}$ de amido gelatinizado na farinha de rosca dificultou a homogeneização devido à aglomeração da amostra, resultando em pedaços maiores do que o necessário para o breading (etapa de cobertura). Portanto, o uso direto desta solução não seria viável. Uma possibilidade para seu uso, seria submeter a farinha de cobertura com $10 \mathrm{~g}$ de amido a uma etapa de secagem e em seguida a um processo de peneiramento para descompactar os aglomerados e assim efetuar a cobertura do produto empanado. Outro aspecto importante que demonstra que a adição de amido favorece uma cobertura ideal aos alimentos empanados é o fato de que farinha de rosca padrão, ou seja, sem adição de amido absorve uma quantidade relativamente 
alta, de gordura $(18,17 \%)$, além de ocasionar em uma perda grande de massa durante o processo de fritura devido ao seu menor tamanho de partícula.

Outro ponto avaliado neste trabalho foi que no processo de fritura no comércio das cidades, muitas vezes ocorre a substituição do óleo de soja pela gordura vegetal hidrogenada $(\mathrm{GVH})$. Assim, como fator de comparação quanto à absorção lipídica foi feito um teste de teor de absorção lipídica com a farinha de rosca tratada com $10 \mathrm{~g}$ de amido utilizando gordura vegetal hidrogenada. De acordo com a Tabela 5 é possível observar que a porcentagem de gordura absorvida pela farinha utilizando-se a gordura vegetal como meio de fritura, foi maior ( 15\%) em comparação com o óleo de soja ( 13\%).

Tabela 5: Teor lipídico da farinha tratada com $10 \mathrm{~g}$ de amido frita em gordura vegetal e em óleo de soja

\begin{tabular}{|c|c|c|c|c|}
\hline \multicolumn{5}{|c|}{ Processo de extração } \\
\hline \hline Amostra & $\begin{array}{c}\text { Gordura } \\
\text { extraída (GVH) }\end{array}$ & $\%$ de gordura & Óleo extraído & $\%$ de óleo \\
\hline $10 \mathrm{~g}$ de amido & 0,8708 & 15,56 & 0,7738 & 13,93 \\
\hline
\end{tabular}

Este resultado é um indicativo de que a utilização do óleo de soja como opção para a fritura de produtos empanados, provavelmente, seja a mais adequada, por ser mais saudável e não conter gordura trans. Além disso, outro fator que deve ser levado em consideração é que a gordura vegetal possui maior porcentagem de gorduras saturadas, totais e trans em comparação com os dados fornecidos pelo fabricante do óleo de soja. Contudo são necessários ainda outros testes a fim de propor que produtos empanados sejam fritos apenas com o óleo de soja.

\section{CONCLUSÃO}

Com base nos resultados obtidos pode-se concluir que a adição de $10 \mathrm{~g}$ da solução de amido de milho $(30 \%)$ à farinha de rosca, reduziu o teor lipídico absorvido durante o processo de fritura. Esta concentração foi suficiente para recobrir as partículas de farinha de rosca e gerar um filme gelatinoso capaz de impedir absorção de gordura entre os poros da farinha.

\section{REFERÊNCIAS BIBLIOGRÁFICAS}

AGÊNCIA NACIONAL DE VIGILÂNCIA SANITÁRIA - ANVISA. Regulamento técnico para óleos e gorduras vegetais. Consulta pública no 85, 2004.

AMERICAN OIL CHEMISTS' SOCIETY - Official methods and recommended praticces of the American Oil Chemists`Society - A.O.C.S, 2009.

DILL, D. D.; SILVA, P. A.; LUVIELMO, M. M. Processamento de empanados: sistemas de cobertura. Estudos Tecnológicos, v.5, n.1, 2009.

FLORES, A.F.; Desenvolvimento de nuggets enriquecidos com fibras e sem adição de glúten. Universidade Federal Tecnológica do Paraná - Curso de tecnologia de alimentos, 2012.

INSTITUTO ADOLFO LUTZ (São Paulo). Óleos e gorduras. In:. Métodos físico-químicos para análise de alimentos. 1a ed digital. São Paulo: Instituto Adolfo Lutz, 2008. p. 593-629. 